\title{
KUALITAS PELAYANAN RESTORAN BALKONDES DI SEKITAR KAWASAN CANDI BOROBUDUR
}

\author{
Ita Maemunah', Ratih Fitria ${ }^{2}$, Dodi Affandi ${ }^{3}$ \\ ${ }^{123}$ Sekolah Tinggi Pariwisata Bandung \\ itamenunah@stp-bandung.ac.id ${ }^{1}$
}

\begin{abstract}
Research on the Service Quality of Balkondes Restaurants around the Borobudur Temple area was carried out to solve the problem of the level of business competition in the market space, as well as the low targets in achieving what Balkondes restaurants must achieve. This research was conducted to identify the wants and needs of restaurant-restaurant customers around Borobudur Temple, so that they can innovate the applied service strategies. This study uses a descriptive research method approach with data collection techniques through interviews; questionnaire; and literature study. The population in this study were balkondes in the Borobudur Temple area with a non-random sample technique, namely accidental sampling. Broadly speaking, the results of this study indicate that customers give good scores on the aspects of ease of location, comfort of the place, speed of presentation, explanation of waiters and attitude of response to customer complaints, while other aspects studied are only given sufficient scores.
\end{abstract}

Keywords: Restaurant, service, balkondes.

\begin{abstract}
Abstrak
Penelitian mengenai Kualitas Pelayanan Restoran Balkondes di sekitar Kawasan Candi Borobudur dilakukan untuk menyelesaikan masalah tingkat persaingan bisnis dalam ruang pasar, serta rendahnya target dalam pencapaian yang restaurant Balkondes harus capai. Penelitian ini dilakukan untuk mengidentifikasi keinginan dan kebutuhan pelanggan restoran-restouran yang berada di sekitar Candi Borobudur, agar dapat melakukan inovasi terhadap strategi pelayanan yang diterapkan. Penelitian ini menggunakan pendekatan metode penelitian deskriptif dengan teknik pengumpulan data melalui wawancara; angket;dan studi pustaka. Populasi dalam penelitian ini adalah balkondes yang terdapat di daerah Candi Borobudur dengan teknik sample non-random, yaitu accidental sampling. Secara garis besar, hasil dari penelitian ini menunjukkan bahwa pelanggan memberikan nilai baik pada aspek kemudahan lokasi, kenyamanan tempat, kecepatan penyajian, penjelasan pramusaji dan sikap respon terhadap keluhan pelanggan, sedangkan pada aspek lain yang diteliti hanya diberikan nilai cukup.
\end{abstract}

Kata kunci: Restoran, pelayanan, balkondes.

\section{A. PENDAHULUAN}

Era digital saat ini mendorong persaingan semakin tinggi karena dapat menimbulkan bisnis-bisnis yang inventif serta memberikan peluang perusahaan untuk meningkat dengan cepat. Ekonomi yang bersifat digital telah merubah ekonomi global, sehingga industri kecil dapat menjadi industri multinasional mikro dengan elastisitas yang dimiliki (Prasetyono, Persaingan di Era Globalisasi dan Ekonomi Digital, 2017). Pertumbuhan bisnis jasa khususnya pariwisata telah mengalami peningkatan yang signifikan, dibuktikan dengan data bahwa sektor pariwisata telah berkontribusi sekitar $4 \%$ dari total perekonomian Indonesia (Indonesia Investment, 2016). Pemerintah Indonesia saat ini sangat mendukung kemajuan sektor pariwisata. Berkali-kali dalam berbagai kesempatan, Presiden Joko Widodo menyampaikan bahwa pemerintah punya target mendatangkan 20 juta wisatawan mancanegara yang harus dicapai pada tahun 2019 (Putri, 2017). Hal mempengaruhi jumlah kunjungan wisatawan mancanegara ke Indonesia yang selalu meningkat setiap tahunnya. Tabel 1 merupakan data kunjungan wisman ke Indonesia: 
Tabel 1 Kunjungan Wisatawan Mancanegara Ke Indonesia Dari 2015-2018

\begin{tabular}{|l|l|l|l|}
\hline \multicolumn{4}{|c|}{ Kunjungan Wisman } \\
\hline $\mathbf{2 0 1 5}$ & $\mathbf{2 0 1 6}$ & $\mathbf{2 0 1 7}$ & $\mathbf{2 0 1 8}$ \\
\hline 10.406. & 11.519 .2 & 14.039 .7 & 15.810 .0 \\
759 & 75 & 99 & 00 \\
\hline
\end{tabular}

\section{Sumber: Ditjen Imigrasi dan BPS (diolah kembali oleh Asdep Litbangjakpar Kemenpar), 2018}

Tingginya prospek yang ada membuat banyak pemain baru dibidang perhotelan ataupun restoran, khusunya diwilayah Candi Borobudur. Saat ini trafik kunjungan wisatawan ke Candi Borobudur setiap tahun, baik domestik maupun mancanegara, berkisar 9 juta orang. Dari jumlah itu, kunjungan wisatawan mancanegara sekitar 600 ribuan orang tiap tahun (https://travel.tempo.com/. April 2019).

BUMN mendirikan Balkondes sebagai sebuah bentuk dukungan untuk menggenjot kunjungan wisatawan di Indonesia. Balkondes (Balai Ekonomi Desa) merupakan sebuah program bentukan BUMN yang akan dimanfaatkan sebagai sebuah etalase bagi perekonomian daerah. Balkondes akan memberikan ruang bagi pemerintah desa maupun masyarakat untuk mengembangkan potensi ekonomi yang ada di desa. Balkondes merupakan salah satu program buatan BUMN selain kemitraan dan CSR (Corporate Social Responsibility) yang berguna meningkatkan kualitas hidup masyarakat Indonesia. Untuk mendukung program ini, BUMN juga membekali masing - masing Balkondes dengan BUMN sponsor. Untuk daerah Borobudur sendiri, sudah ada 20 Balkondes yang dibuat oleh BUMN.

Saat ini terdapat lebih dari 80 Restoran dan rumah makan yang menjalankan usaha di Kabupaten Magelang. Wisatawan menilai produk-produk yang mereka tawarkan dengan banyak aspek, sehingga para wisatawan memiliki keinginan dan kebutuhan yang berbeda dan manajemen restoran dituntut untuk selalu memperbaiki kinerjanya. Adanya globalisasi dan inovasi teknologi yang terus berkembang juga mengharuskan perusahaan, termasuk restoran untuk terus meningkatkan kualitas produknya agar tetap bertahan dalam persaingan. Para produsen berlomba-lomba dalam berbagai aspek termasuk biaya, layanan konsumen, waktu dalam berinovasi, dan kualitas atau mutu, untuk dapat diterima masyarakat.

QFD sebagai metodologi untuk menangkap atau menerjemahkan suara pelanggan (Voice of customer) ke dalam karakteristik teknis dari produk ataupun jasa. QFD digunakan untuk mengetahui ke dalam karakteristik pelayanan di restoran. Metode QFD dapat dikombinasikan dengan metode Kano didalam membahas atributatribut yang menjadi kebutuhan dan keinginan pelanggan.

\section{B. Tinjauan Pustaka}

\section{Restoran}

Merupakan tempat untuk makan dan minum yang disediakan bagi konsumen yang ingin menikmati suasana tempat makan dan minum yang berbeda dengan berbagai maksud dan tujuan serta memiliki fasilitas penunjang kenyamanan konsumen seperti toilet, area parkir dan mushola dengan dikelola secara professional untuk mendapatkan pelanggan dan keuntungan. Menurut Cousin dkk (2002) dan Dittmer (2002) Faktor - faktor produk restoran diantaranya makanan dan minuma; pelayanan; kebersihan dan higienitas; harga; dan atmosfer/suasana.

\section{Pelayanan}

Menurut Kotler (2012) pelayanan adalah setiap tindakan atau kegiatan yang dapat ditawarkan oleh suatu pihak kepada pihak lain, yang pada dasarnya tidak berwujud dan tidak mengakibatkan kepemilikan apapun. kualitas pelayanan dapat diartikan sebagai upaya

24 | Barista: Jurnal Kajian Bahasa dan Pariwisata, Volume 6 Nomor 1, 2019: 23-32 
pemenuhan kebutuhan dan keinginan konsumen serta ketepatan penyampaiannya dalam mengimbangi harapan konsumen (Tjiptono \& Chandra 2005). Rangkuti (2002:29) menjelaskan bahwa terdapat 10 kriteria umum atau standar yang menentukan kualitas suatu jasa, yaitu: (1) reliability (keandalan), (2) responsiveness (ketanggapan), (3) competence (kemampuan), (4) acces (mudah diperoleh), (5) courtesy (keramahan), (6) communication (komunikasi), (7) credibility (dapat dipercaya), (8) security (keamanan), (9) understanding/knowing the customer (memahami palanggan), (10) tangibles (bukti nyata).

\section{Quality Function Deployment (QFD)}

Pengertian QFD Quality Function Deployment (QFD) adalah metode perencanaan dan pengembangan produk/jasa secara terstruktur yang memungkinkan tim pengembang mendefinisikan secara jelas kebutuhan dan harapan tersebut dan mengevaluasi kemampuan produk atau jasa secara sistematik untuk memenuhi kebutuhan dan harapan tersebut (Wahyu,2003). Dalam QFD dilaksanakan dengan menyusun satu atau lebih matrik yang disebut The House Of Quality. Matrik ini menjelaskan apa saja yang menjadi kebutuhan dan harapan pelanggan dan bagaimana memenuhinya. Matrik tersebut secara umum dapat dilihat pada gambar 1 .

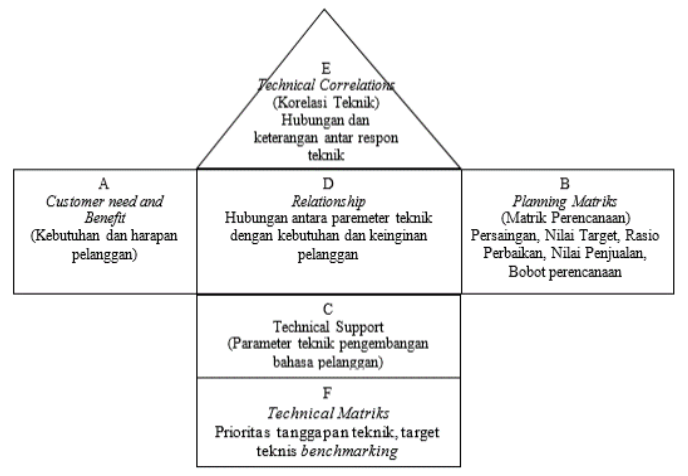

Gambar 1 The House of Quality

Sumber Cohen (1995: 187) dalam Endang \& Suroto ( 2014 : 376)

\section{Metodologi Penelitian}

Pendekatan dalam penelitian ini adalah metode penelitian deskriptif. Kata deskriptif dibentuk dari kata kerja bahasa Inggris to describe yang berarti "menggambarkan" sesuatu. Sugiono (2006:11) menjelaskan bahwa "Penelitian desktiptif adalah penelitian yang dilakukan untuk mengetahui nilai variabel mandiri, baik satu variabel atau lebih tanpa membuat perbandingan atau menghubungkan dengan variabel yang lain". Teknik Pengumpulan data yang dilakukan menggunakan wawancara, angket dan studi literature, sedangkan populasi yang diambil adalah Balkondes dengan teknik sampel accidental sampling.

Data yang telah dikumpulkan selanjutnya dianalisis lebih lanjut untuk memperoleh hasil yang dijadikan jawaban dari permasalahan penelitian. Dalam menganalisis data penelitian ini digunakan metode deskriptif yang menjabarkan gambaran umum perusahaan. Sedangkan untuk menganalisis kualitas pelayanan Restoran digunakan metode QFD melalui matriks HOQ. Alat analisis yang digunakan 
untuk mengolah data-data dalam penelitian ini adalah analisis Microsoft Office Excel 2010. Pengukuran tingkat kepentingan dan tingkat kepuasan menggunakan skala lima peringkat (Skala Likert). Menurut Simamora (2002), Skala Likert merupakan teknik pengukuran sikap yang paling luas digunakan dalam riset pemasaran.

Sedangkan untuk metode analisis Quality Function Deployment yang merupakan sebuah alat perencanaan yang digunakan untuk memenuhi harapan konsumen terhadap produk. Alat perencanaan utama dalam matriks Quality Fuction Deployment adalah House of Quality (HOQ). HOQ menerjemahkan suara konsumen ke dalam persyaratan teknis bagaimana cara organisasi agar dapat memenuhi persyaratan tersebut.

\section{HASIL PENELITIAN}

Penerapan metode QFD diawali dengan pembentukan House of Quality (HOQ). Matriks ini menerjemahkan apa yang diinginkan konsumen menjadi apa yang dihasilkan organisasi sehingga produk yang dihasilkan akan dapat memenuhi keinginan konsumen. Langkah-langkah penyusunan matriks HOQ dalam peningkatan pelayanan restoran Balkondes terdiri dari langkah-langkah mendaftarkan persyaratan pelanggan (customer requirements), mendaftarkan persyaratan teknik (technical requirements), mengembangkan matriks hubungan persyaratan pelanggan dengan persyaratan teknik (interrelationships matrix), mengembangkan matriks korelasi persyaratan teknik (correlation matrix), mengembangkan matriks perencanaan (planning matriks) dan mengembangkan matriks target (target matrix).

Berdasarkan data yang diperoleh hasil pada persyaratan teknis dapat dilihat melalui table 2.

Tabel 2 Persyaratan Pelanggan Restoran Balkondes

\begin{tabular}{|l|l|}
\hline \multicolumn{1}{|c|}{ Persyaratan Pelanggan } & $\begin{array}{c}\text { Tingkat } \\
\text { Kepuasan }\end{array}$ \\
\hline Rasa & 3 \\
\hline Tampilan Makanan dan Minuman Menarik & 3 \\
\hline Kehigienisan Makanan dan Perlengkapannya & 3 \\
\hline Porsi makanan dan Minuman & 3 \\
\hline Keragaman dan Variasi Menu & 3 \\
\hline Harga & 3 \\
\hline Kemudahan Lokasi & 4 \\
\hline Kenyamanan Tempat & 4 \\
\hline Tempat Parkir Luas dan Nyaman & 3 \\
\hline Dekorasi Ruangan & 4 \\
\hline Kebersihan Ruangan & 3 \\
\hline Kecepatan Penyajian & 3 \\
\hline Keramahan dan Kesopanan Pramusaji & 5 \\
\hline Penampilan Pramusaji & 3 \\
\hline Penjelasan Pramusaji & 3 \\
\hline Respon keluhan Pelanggan & 4 \\
\hline Kecepatan Transaksi & 4 \\
\hline Iklan dan Promosi & 3 \\
\hline
\end{tabular}

Sumber : Olahan Kuesioner 2019 
Setelah kebutuhan dan harapan konsumen dinyatakan dalam persyaratan pelanggan, langkah kedua dalam membangun matriks $\mathrm{HOQ}$ adalah mendaftarkan persyaratan teknik yang akan mempengaruhi satu atau lebih persyaratan pelanggan.

Arah pengembangan atau direct of improvement (DOI) dari setiap persyaratan teknik penting untuk ditentukan karena informasi tersebut akan sangat membantu dalam penentuan korelasi antar persyaratan teknik dalam penentuan target.

Tabel 3 Arah Pengembangan

\begin{tabular}{|l|l|c|}
\hline No & Persyaratan Teknik Primer & $\begin{array}{c}\text { Arah } \\
\text { Pengembanga } \\
\text { n }\end{array}$ \\
\hline 1. & Suplai Bahan Baku & \\
\hline 2. & Penyimpanan Bahan Baku & 4 \\
\hline 3. & Preparasi & 4 \\
\hline 4. & Pemasakan & 4 \\
\hline 5. & Pelayanan & 4 \\
\hline 6. & Pembersihan Ruang & 4 \\
\hline 7. & Pencucian (Washing) & 4 \\
\hline
\end{tabular}

Berdasarkan pada Tabel 3 diketahui bahwa semua arah pengembangan persyaratan teknik Restoran Balkondes mempunyai arah pengembangan ditingkatkan, Hal tersebut karena pihak Balkondes selalu berorientasi pada penambahan jumlah konsumen dari waktu ke waktu, sehingga baik kapasitas pengolahan produk dan pelayanan akan terus ditingkatkan.

Langkah selanjutnya dalam penyusunan HOQ adalah membandingkan persyaratan pelanggan dengan persyaratan teknik, kemudian menentukan hubungan antara kedua persyaratan dalam matriks interrelationships. Gambar 2 merupakan hubungan antara kedua persyaratan dalam matriks interrelationship:

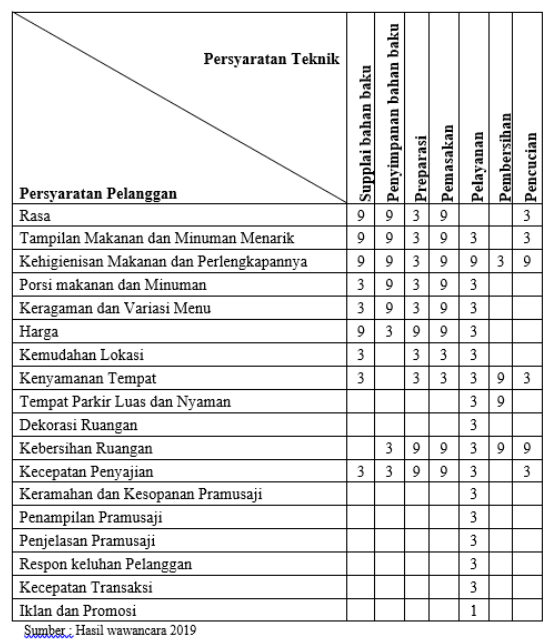

Gambar 2 Matriks Hubungan Persyarat Pelanggan dengan Persyaratan Teknik 
Sementara untuk menjawab matriks hubungan antar persyaratan teknik (how) memiliki fungsi untuk mengidentifikasi persyaratan teknik mana saja yang saling mendukung dan saling bertentangan satu sama lainnya.

Persyaratan teknik yang saling bertentangan sangat penting karena persyaratan teknik tersebut secara teratur merupakan hasil dari persyaratan pelanggan dan konsekuensinya menunjukkan titik dimana trade off harus dibuat.

Berdasarkan wawancara dengan Pengelola / Manajer Restoran Balkondes dapat diketahui hubungan antar persyaratan teknik atau matrik correlations.

Matriks hubungan antar persyaratan teknis dapat dilihat pada Gambar 3.

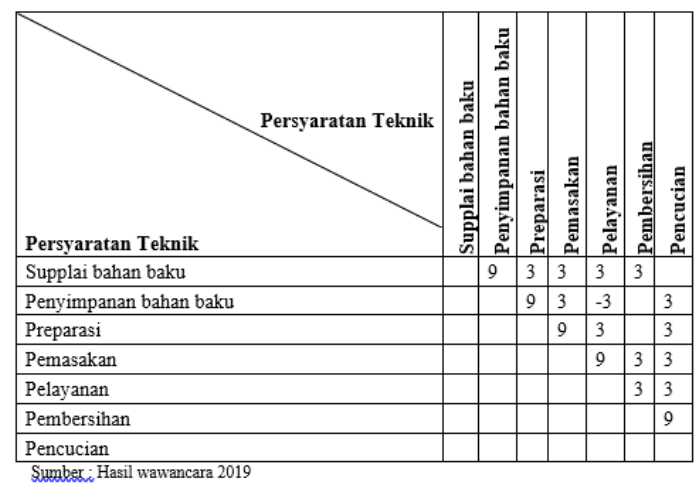

\section{Gambar 3 Matriks Hubungan Antar Persyaratan Teknik Restoran Balkondes}

Penelitian terhadap 100 konsumen Balkondes yang sedang makan di Balkondes. Dari 100 responden tersebut, kemudian dipilih tiga puluh orang yang pernah mengunjungi Balkondes. Responden diminta untuk mengurutkan dan memberikan peringkat pada masing- masing persyaratan pelanggan sesuai dengan tingkat kepuasan yang diarasakanya. Penilaian kompetitif pelanggan bagi konsumen Balkondes dapat dilihat pada Tabel 4.

Tabel 4 Matriks Kompetitif Persyaratan Pelanggan

\begin{tabular}{|l|c|c|}
\hline \multirow{2}{*}{ Persyaratan Pelanggan } & \multicolumn{2}{c|}{ Penilaian Kompetitif } \\
\cline { 2 - 3 } & Balkondes & Pesaing \\
\hline Rasa & 3 & 5 \\
\hline Tampilan Makanan dan Minuman Menarik & 3 & 4 \\
\hline Kehigienisan Makanan dan Perlengkapannya & 3 & 4 \\
\hline Porsi makanan dan Minuman & 3 & 4 \\
\hline Keragaman dan Variasi Menu & 3 & 4 \\
\hline Harga & 3 & 3 \\
\hline Kemudahan Lokasi & 4 & 3 \\
\hline Kenyamanan Tempat & 4 & 3 \\
\hline Tempat Parkir Luas dan Nyaman & 3 & 4 \\
\hline Dekorasi Ruangan & 4 & 5 \\
\hline Kebersihan Ruangan & 3 & 4 \\
\hline Kecepatan Penyajian & 3 & 4 \\
\hline Keramahan dan Kesopanan Pramusaji & 5 & 5 \\
\hline Penampilan Pramusaji & 3 & 4 \\
\hline Penjelasan Pramusaji & 3 & 4 \\
\hline Respon keluhan Pelanggan & 4 & 4 \\
\hline Kecepatan Transaksi & 4 & 4 \\
\hline Iklan dan Promosi & 3 & 5 \\
\hline
\end{tabular}

Pada aspek Tingkat kepentingan, Persyaratan - persyaratan yang disebutkan memiliki kepentingan bagi para pelanggan dimana aspek - aspek yang dinilai mulai dari rasa makanan dan minuman, tampilan makanan dan minuman yang menarik, kehigienisan makanan dan perlengkapannya, porsi makanan dan minuman, keragaman dan variasi menu, harga, kemudahan lokasi, kenyamanan tempat, tempat parkir luas dan nyaman, dekorasi ruangan, kebersihan ruangan, kecepatan dalam 
penyajian, keramahan dan kesopanan pramusaji, penampilan pramusaji, penjelasan pramusaji, menanggapi respon keluhan pelanggan, kecepatan dalam melakukan transaksi, dan adanya kegiatan promosi sebagai media informasi dan komunikasi restoran dengan konsumennya. Secara garis besar, tingkat kepentingan dari setiap aspek yang dnilai dapat dilihat melalui table 5 :

\section{Tabel 5 Tingkat Kepentingan SetiapPersyaratan Pelanggan Restoran Balkondes}

\begin{tabular}{|l|c|}
\multicolumn{1}{|c|}{ rersyaratau reianggan } & 1 шgкаи nерепинап \\
\hline Rasa & 4 \\
\hline Tampilan Makanan dan Minuman Menarik & 3 \\
\hline Kehigienisan Makanan dan Perlengkapannya & 5 \\
\hline Porsi makanan dan Minuman & 4 \\
\hline Keragaman dan Variasi Menu & 4 \\
\hline Harga & 4 \\
\hline Kemudahan Lokasi & 5 \\
\hline Kenyamanan Tempat & 4 \\
\hline Tempat Parkir Luas dan Nyaman & 4 \\
\hline Dekorasi Ruangan & 5 \\
\hline Kebersihan Ruangan & 5 \\
\hline Kecepatan Penyajian & 3 \\
\hline Keramahan dan Kesopanan Pramusaji & 4 \\
\hline Penampilan Pramusaji & 4 \\
\hline Penjelasan Pramusaji & 5 \\
\hline Respon keluhan Pelanggan & 3 \\
\hline Kecepatan Transaksi & 4 \\
\hline Iklan dan Promosi & 4 \\
\hline Sumbi Olahan Kuesioner 2019
\end{tabular}

Sumber : Olahan Kuesioner 2019

Pada aspek nilai sasaran pelanggan yang ditentukan dengan mengevaluasi penilaian dari setiap persyaratan pelanggan dan membuat pilihan baru untuk mempertahankan produk dan pelayanan agar tidak berubah, memperbaiki produk atau membuat produk lebih baik dari pada pesaingnya. Berdasarkan hasil temuan, nilai sasaran setiap persyaratan pelanggan, Balkondes ingin mempertahankan kehigienisan makanan dan perlengkapannya sebagai upaya menjaga kepercayaan kepada konsumen kemudian keramahan dan kesopanan pramusaji dimana hal ini merupakan hal yang diperhatikan manajemen kepada seluruh pegawai sebagai cara menimbulkan kesan yang bersahabat kepada konsumen untuk menjaga loyalitasnya dimasa yang akan datang, selanjutnya kemudahan lokasi merupakan keuntungan tersendiri dikarenakan keadaan Balkondes yang berdekatan dengan objek pariwisata dan sebagian besar konsumen adalah wisatawan.

Terakhir, pada aspek mengembangkan urutan prioritas persyaratan teknik, dilihat melalui penilaian kompetitif teknik yang dilakukan dengan membandingkan kinerja persyaratan teknik perusahaan dengan pesaingnya, yaitu membandingkan Restoran Balkondes dengan restoran lainnya sekitar area Borobudur. Dalam penilaian ini digunakan skala likert lima angka, yaitu 1 untuk yang sangat buruk dan 5 untuk sangat baik. Berdasarkan hasil wawancara dengan manajemen Restoran Balkondes diketahui penilaian kompetitif teknik Restoran Balkondes secara menyeluruh dinilai belum baik dari pada pesaingnya.

Sedangkan dari aspek nilai sasaran persyaratan teknik, sebagai berapa banyak nilai yang diambil untuk memenuhi atau melebihi harapan pelanggan yang dijawab dengan mengavuasi semua informasi yang dimasukkan ke dalam matriks HOQ. Berdasarkan hasil wawancara dengan manajemen Restoran Balkondes diketahui nilai sasaran yang ditetapkan Restoran Balkondes adalah Restoran Balkondes ingin meningkatkan persyaratan teknik penyimpanan bahan baku, preparasi dan pemasakan memiliki penilaian kurang dari pada pesaing menjadi minimal sama dengan pesaing. 


\section{E. SIMPULAN}

Pelanggan memberikan nilai baik pada kemudahan lokasi, kenyamanan tempat, kecepatan penyajian, penjelasan pramusaji dan adanya respon keluhan pelanggan sedangkan pada aspek lainnya memberikan penilaian cukup.

Berdasarkan bobotabsolut persyaratan pelanggan yang perlu diprioritaskan karena memilki bobot absolut tinggi yaitu kehigienisan makanan dan minuman yang memang merupakan tutntutan kosumen akan kesehatan dan kebersihan makanan yang disajikan sealin itu adalah lokasi yang strategis menjadi keunggulan dari Restoran Balkondes yang harus terus dibenahi akses dan petunjuk arahnya oleh pihak pengelola. Sedangkan berdasarkan perhitungan nilai absolut persyaratan teknik, prioritas persayaratan teknik yang paling perlu diperbaiki adalah pemasakan dan pelayanan.

\section{Saran}

Untuk memperbaiki kualitas layanannya, Restoran Balkondes harus memilki standar rasa yang khas yaitu dengan cara memperbaiki proses suplai bahan baku, penyimpanan bahan baku, preparasi, dan pemasakan. Selanjutnya adalah kenyamanan dengan cara memperbaiki persyaratan teknik pelayanan dan pembersihan ruangan, yaitu dengan rutin melakukan kegiatan pembersihan secara menyeluruh dan melibatkan semua pihak dengan terjadwal secara periodic misalkan satu bulan sekali. Untuk memperbaiki persyaratan pelanggan harga dan variasi menu, persyaratan teknik yang harus diperbaiki adalah menjaga ketersedian suplai bahan baku, penyimpanan bahan baku yang baik dan pengolahan makananan sesuai dengan standar resep yang telah dityentukan oleh manajemen. Persyaratan pelanggan penjelasan pramusaji, respon dan keluhan pelanggan diperbaiki dengan cara diberikan pelatihan dan mendapatkan penjelasan mengenai teknik dan cara berhadapan dengan konsumen secara baik dan benar. Persyaratan pelanggan kehigienisan makanan dan perlengkapannya selalu terjaga konsistensi dean selalu memperhatikan dan perawatan peralatan dalam proses pencucian dan preparasi.

Kemudahan lokasi dan tempat parkir yang cukup menampung kendaraan konsumen dan aman merupakan bentuk pelayanan yang perlu dijaga konsistensinya. Persyaratan pelanggan penataan eksterior dan interior ruangan diperbaiki dengan cara memperbaiki atribut pelayanan dan pembersihan ruangan.

Kecepatan pramusaji dalam memberikan pelayanan kepada konsumen selalu terus diperbaiki dan dievaluasi termasuk kerjasama dengan phak dapur sebagai penyedia makanan dan minuman yang tidak dipungkiri ketersediaan suplai bahan baku, penyimpanan bahan baku, proses preparasi dan pemasakan dapat menjadi kendala dalam keceapatan pramusaji dalam memberikan pelayanan.

Kecepatan transaksi, keramahan dan kesopanan, penampilan pramusaji selalu diperhatikan dan dievaluasi serta secara periodeik diberikan pelatihan untuk menjaga konsistensi pelayanan kepada konsumen.

Persyaratan pelanggan porsi makanan dan minuman dan tampilan menu yang disajikan kepada konsumen selalu terjaga sesuai dengan standar resep yang telah ditentukan oleh manajemen ditunjang pula dengan menjaga proses suplai bahan baku, penyimpanan, dan preparasi serta teknik memasak.

Manajemen Balkondes perlu melakukan survei kepuasan pelanggan setiap bulannya, untuk mengetahui dan mengevaluasi kebutuhan, keinginan dan permintaan konsumen agar dapat meningkatkan kualitas produk dan pelayanan. Karena lingkungan usaha restoran yang selalu dinamis membutuhkan perbaikan yang terus menerus dari waktu ke waktu dalam peningkatan mutu. 


\section{DAFTAR PUSTAKA}

Arini, Wahyu. 2003. Manajemen Kualitas . Ghalia Indonesia. Jakarta.

Chang, K.-C., \& Chen, M.-C. (2011). Applying The Kano Model and QFD to Explore Customer Brand's Contacts in The Hotel Business : A Study of Hot Spring Hotel. Total Quality Management \& Business Excellent, 3.

Cohen, L. 1995. Quality Function Deployment: How To Make QFD Work For You. Addison Wesley Publishing Co.

Gaspersz,V. 2001. Analisa Untuk Peningkatan Kualitas. Penerbit PT.Gramedia Pustaka Utama.

Groover, M. P. 2005. Otomasi, Sistem Produksi, dan Computer-Integrated Manufacturing, Edisi Kedua, jilid 1. Alih bahasa oleh Gunarta, I. K., Arthaya, B. Guna Widya, Surabaya.

H.A.S, Moenir. 1998. Manajemen Pelayanan Umum Di Indonesia . Jakarta: Bumi Aksara

Hasan, Ali. 2015. Tourism Marketing. Cetakan 1. Yogyakarta. CAPS.

Hidayati, E. D. (2017). Analisis Kebutuhan dan Perancangan Layanan Jasa Penginapan Hotel XYZ Menggunakan Integrasi SERVQUAL, Model Kano dan Service Blue Print.

Izwaan, M. S. (2012). The Effectiveness of Integrating Kano Model and Servqual into Quality Function Deployment (QFD) for Developing Training Couses Model. Journal of WEI Business and Economics.

Kamus Besar Bahasa Indonesia, 2011

Kim, Sangsoo et.al. 2008. VIRE: Sailing a Blue Ocean with Value-Innovative Requirements Engineering. IEEE Software.

Kim, W.C., dan R Mauborgne. 2006. Blue Ocean Strategy: Ciptakan Ruang Pasar Tanpa Pesaing dan Biarkan Kompetisi Tak Lagi Relevan. Jakarta: PT. Serambi Ilmu Semesta

Nasution, M. N.2005. Manajemen Mutu Terpadu (Total Quality Management) Edisi kedua. Jakarta : Ghalia Indonesia.

Paryani, Kioumars, et.al. 2010. QFD Application in the Hospitality Industry: A Hotel Case Study. South Branch of Tehran: Azad University.

Prasetyono, A. P. (2017, November 13). Persaingan di Era Globalisasi dan Ekonomi Digital. Retrieved from Kementerian Riset Teknologi dan Pendidikan Tinggi Republik Indonesia:

Prasetyono, A. P. (2017, November 13). www.risetdikti.go.id. Retrieved February 19, 2018

Putri, A. W. (2017, Oktober 19). Menjadikan Pariwisata sebagai Core Business Indonesia. Retrieved from Wonderful Indonesia Co-Branding Forum: https://swa.co.id/wicf/news/menjadikanpariwisata-sebagai-core-business-indonesia

Rahmana, A., Kamil, M., Soemantri, E., \& Olim, A. (1997). Integration of SERVQUAL and KANO Model Into QFD to Improve Quality of Simulation-Based Training on Project Management. International Journal of Basic and Applied Science.

Rangkuti, F. 2002. Measuring Customer Satisfaction (Cetakan Ketiga). Jakarta: PT. Gramedia Pustaka Utama.

Tan, K. C., \& Pawitra, T. A. (2001). Integration SERVQUAL and Kano's model into QFD for service excellent development. Managing Service Quality: An International Journal.

Tjiptono dan chandra. 2005. Service Quality and Satisfaction . Edisi 2. Andi, Yogyakarta.

Ulrich, K. T., \& Eppinger, S. D. (2012). Product Design and Development Product Design and Development.

http://magelangkab.go.id/images/dokumen/d4d92cb1b01346efe34ad84e35c9df5c.pdf

https://jateng.bps.go.id/statictable/2017/10/30/1619/jumlah-restoran-rumah-makanmenurut-kabupaten-kota-di-provinsi-jawa-tengah-2012-2016.html

https://regional.kompas.com/read/2018/11/23/21012641/kawasan-candi-borobudurdiusulkan-jadi-cagar-biosfer-dunia

https://ristekdikti.go.id/persaingan-di-era-globalisasi-dan-ekonomi-digital/

https://travel.tempo.co/read/1193551/nyia-dongkrak-kunjungan-wisatawan-mancanegara-kecandi-borobudur/full\&view $=$ ok 
https://www.tripadvisor.co.id/Restaurants-g790291-

Borobudur_Magelang_Central_Java_Java.html

Humas Sekertariat Kabinet Republik Indonesia. (2017, Januari 6). Tahun 2017 Kita Genjot Sektor Pariwisata. Retrieved from Sekretariat Kabinet Republik Indonesia: http://setkab.go.id/tahun-2017-kita-genjot-sektor-pariwisata/ 